\title{
Seasonal and diurnal variations of carbonyl compounds in Beijing ambient air
}

\author{
Xiaobing Pang, Yujing $\mathrm{Mu}^{*}$ \\ State Key Laboratory of Environmental Chemistry and Ecotoxicology, Research Center for Eco-Environmental Sciences, \\ Chinese Academy of Sciences, Beijing 100085, China
}

Received 17 November 2005; received in revised form 15 May 2006; accepted 18 May 2006

\begin{abstract}
The levels of carbonyl compounds in Beijing ambient air were measured from November 2004 to October 2005. Formaldehyde, acetaldehyde and acetone were found to be the most abundant carbonyls. The concentrations of formaldehyde, acetaldehyde and acetone increased to $19.51 \pm 6.34,17.18 \pm 4.57,22.14 \pm 5.98 \mathrm{\mu g} \mathrm{m}^{-3}$, respectively, in summer from $5.14 \pm 2.56,8.68 \pm 3.48,9.18 \pm 3.27 \mu \mathrm{g} \mathrm{m}^{-3}$ in winter. Carbonyls showed excellent correlations with ozone in summer and significant correlations with $\mathrm{CO}$ in winter, which indicated that the sources of carbonyls were dominated by photo-oxidation of VOCs in summer and vehicular exhaust in winter. The photolysis rates of lower carbonyls calculated based on local zenith angle were one magnitude greater in summer than in winter. The distribution frequencies of carbonyls were analyzed from a database including 350 samples. The concentrations of the highest frequency were $9.0-19.0,5.0-15.0$ and $13.0-23.0 \mu \mathrm{g} \mathrm{m}^{-3}$ for formaldehyde, acetaldehyde and acetone, respectively.
\end{abstract}

(C) 2006 Elsevier Ltd. All rights reserved.

Keywords: Carbonyl compounds; Photo-oxidation; Vehicular exhaust; Ozone

\section{Introduction}

Carbonyl compounds (carbonyls) are ubiquitous in urban atmosphere, and emitted directly from incomplete combustion of biomass and fossil fuel and formed indirectly by atmospheric photo-oxidation of volatile organic compounds (VOCs) emitted from anthropogenic and natural sources (Possanzini et al., 2002; Grosjean et al., 1996).

Carbonyls play a pivotal role in the atmospheric photochemistry because they are almost obligatory

\footnotetext{
*Corresponding author. Tel.: + 861062849125 ; fax: + 861062923563 .

E-mail address: yjmu@mail.rcees.ac.cn (Y. Mu).
}

intermediates of the photo-oxidation of hydrocarbons. Carbonyls are the direct precursors of peroxyacylnitrates and ozone through peroxyradicals $\left(\mathrm{HO}_{2}\right.$ and $\left.\mathrm{RO}_{2}\right)$ and $\mathrm{RC}(\mathrm{O}) \mathrm{O}_{2}$ generated by the carbonyls photolysis or reaction with $\mathrm{OH}$ radicals (Finlayson-Pitts and Pitts, 1986; Lary and Shallcross, 2000). In addition, some carbonyls are irritants of the skin, eyes and nasopharyngeal membranes and toxic to human health. More seriously, formaldehyde and acetaldehyde are suspected carcinogens and mutagenic to humans (WHO, 1987).

Considering the important roles of carbonyls in atmospheric photochemistry and their negative impact on human health, the concentration of atmospheric carbonyls and their variability can be 
an effective indicator reflecting the status of local photochemical activity and air pollution. In recent years, many investigations were conducted in some cities and rural areas (Possanzini et al., 2002; Nguyen et al., 2001; Grosjean et al., 2002; Moussa et al., 2006; Feng et al., 2005; Báez et al., 2001). However, to our knowledge, there is still no report about the ambient carbonyls in Beijing city. As the forthcoming 2008 Olympic Games will be held in Beijing, the urban atmospheric quality of Beijing has become a major concern in the world. In recent years, Beijing has aroused wide attention in the world for its photochemical smog (Jacobson, 2002). Therefore, the air pollution of carbonyls in Beijing urgently needs to be investigated. In this study, the major objective was to recognize the pollution levels of carbonyls in Beijing. In addition, the photolysis rates of carbonyls were calculated based on local zenith angles.

\section{Experimental}

\subsection{Sampling sites}

Beijing city $\left(39.8^{\circ} \mathrm{N}, 116.5^{\circ} \mathrm{E}\right)$ is located at temperate zone with half-moist continent monsoon climate. The weather is hot and humid in summer, e.g., average air temperature of $25.9{ }^{\circ} \mathrm{C}$ in July, and is cold and dry in winter, e.g., average air temperature of $-4.3{ }^{\circ} \mathrm{C}$ in January (http:// www.cma.gov.cn). Seasonal variations of air temperature and solar irradiation will affect photochemical activities, which result in different partition of primary and secondary pollutants in the atmosphere.

In this study, air samples were collected at five sampling sites, which are urban ambient site (S1), botanical park site (S2), commercial site (S3), transport hub site (S4), and suburban site (S5). One-year sampling was only conducted in the urban ambient site (S1), the air samples at the other four sampling sites were only conducted in spring (March-April 2005) to recognize the impact of local sources of carbonyls on their concentration. The position of the five sampling sites in Beijing is shown in Fig. 1. Detailed information about those sampling sites is as follows:

(S1) Urban ambient site was chosen on a rooftop (about $25 \mathrm{~m}$ above ground) in the Research Center for Eco-Environmental Sciences (RCEES), which is located between the north fourth-ring road and the north fifth-ring road of Beijing. The RCEES has an

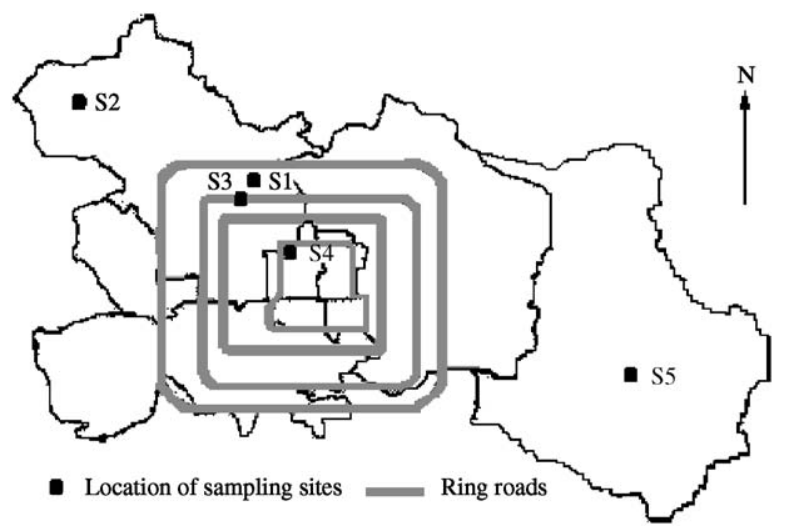

Fig. 1. The position of five sampling sites in Beijing. (S1): Urban ambient site; (S2): botanical park site; (S3): commercial area site; (S4): transport hub site; (S5): suburban site.

area of about $50,000 \mathrm{~m}^{2}$ and is fully covered by various plants, and is surrounded by some institutes, campuses, residential areas, and two side roads with moderate traffic. There are three laboratory buildings and one office building. Various chemical regents are used for experiments in the laboratories.

(S2) Botanical park site (Xiangshan Park) is about $28 \mathrm{~km}$ away from Beijing city and fully covered by various vegetables. Air sampling was conducted at a hill peak $(557 \mathrm{~m})$ in the park only for 2 consecutive days (7-8 April). During sampling time, the weather was sunny and windy, with an average speed of $3 \mathrm{~m} \mathrm{~s}^{-1}$.

(S3) Commercial site (Zhongguancun) is the biggest computer market in Beijing. There is high traffic flow and high density of population in the daytime. Air sampling was performed during 13-16 March 2005, with sunny weather.

(S4) Transport hub site (Xizhimen), links the north second-ring road to the west second-ring road. There are cloverleaf junction, bus stations, subway station and railway station around this site. This sampling site is one of the most heavily trafficpopulated areas in Beijing with a high traffic volume of more than 500,000 vehicles per day. Air sampling was performed during 21-23 March 2005, with sunny weather.

(S5) Suburban site (Tongzhou) is located in the east of Beijing (about $30 \mathrm{~km}$ away from Beijing city). The site is close to a forest belt and at least $2 \mathrm{~km}$ away from the nearest town (Tongzhou). Air sampling was performed during 19 April 2005, with sunny weather. 


\subsection{Carbonyls sampling and analysis}

Samples were collected at 1-h intervals on the sunny days from 8:00 to 20:00 h (Beijing time, BT). The carbonyls in the atmosphere were collected with 2,4-dinitrophenylhenylhydrazine (DNPH)coated Sep-Pak silica gel cartridges (Waters, USA) at a flow of $1.0 \mathrm{~L} \mathrm{~min}^{-1}$ by a sampling minipump (Spectrex, USA). The collection efficiencies were over $98.0 \%$ for the three carbonyls for $1-\mathrm{h}$ sampling. To eliminate the interference of ozone, a KI scrubber (Waters, USA) was connected to the upstream end of the coated cartridge. After sampling, the cartridges were sealed with silicon caps immediately, and stored in a refrigerator before being analyzed. The hydrazones formed by carbonyls and DNPH were eluted slowly from the cartridges with $5.0 \mathrm{~mL}$ acetonitrile and the extracts were analyzed by a HPLC system (Hewlett-Packard 1050) with a UV/Vis detector at $360 \mathrm{~nm}$. The analytical conditions were as follows: Thermo ODS Hypersil column $(5 \mu \mathrm{m}$, $250 \times 5.0 \mathrm{~mm}$ ); gradient mobile phase: $0-14 \mathrm{~min}$ from $60 \%$ to $100 \%$ acetonitrile, and $40 \%$ to $0 \%$ water; mobile-phase flow rate: $1.0 \mathrm{~mL} \mathrm{~min}^{-1}$; injection volume: $10 \mu \mathrm{L}$. The standard solution containing 15 DNPH derivatives (Supelco, USA) was used to identify and quantify carbonyls in all samples. Relative standard deviations were less than 5.0\% for all carbonyls identified. The detection limit $(S / N=3)$ by this method was in the range of $100-300 \mathrm{ng} \mathrm{m}^{-3}$ for various carbonyls of $60 \mathrm{~L}$ sampling volume.

Ambient ozone and carbon monoxide were monitored with a TECO49 ozone analyzer (Thermo Environment Ins, USA) and ML9830 Series carbon monoxide analyzer (Monitor Labs).

\section{Results and discussion}

\subsection{Average diurnal variation in each season}

Nine carbonyls were identified in Beijing ambient air, including formaldehyde, acetaldehyde, acetone, propionaldehyde, benzaldehyde, butyraldehyde, hexaldehyde, tolualdehyde and valeraldehyde. Among the carbonyls, formaldehyde, acetaldehyde and acetone were by far the principal carbonyls. Only the three carbonyls were discussed in this study.

Fig. 2 shows the average diurnal variations of formaldehyde, acetaldehyde and acetone in each season in Beijing urban ambient site (S1). The profiles were obtained by averaging 15-day diurnal data for spring, 6-day for summer, 5-day for autumn, and 4-day for winter. As is well known, urban ambient carbonyl concentrations are greatly influenced by many factors such as direct and indirect sources (mainly from vehicular exhaust and photo-oxidation of hydrocarbons), and meteorological conditions (especially wind speed), and their sinks (photodecomposition, reaction with $\mathrm{OH}$ and dry deposition, etc.). To some extent, the diurnal variation could reflect the influence of these multiple factors on the measured carbonyls concentrations. The significantly elevated carbonyls concentrations in daytime for seasons other than winter strongly suggested that local photo-oxidation of hydrocarbons might be the dominant source of carbonyls in the Beijing air. In winter, only a small elevation of the concentrations of carbonyls in noontime $(11: 00-14: 00 \mathrm{~h}, \mathrm{BT})$, the obvious increment of carbonyls concentration appeared during 17:00-18:00 h (BT) (the rush hours in Beijing), implied that vehicular exhaust might be the primary source of carbonyls in winter. Among the four seasons, the distinct diurnal variation of carbonyls concentrations, as the solar radiation, is only observed in autumn. The meteorological conditions in autumn were relatively stable compared with other seasons, and had less impact on the measured carbonyls concentrations. The distinct diurnal variation of carbonyls concentrations provided strong evidence that local photooxidation of hydrocarbons is the dominant source of carbonyls in the air in Beijing. It should be noted that the time of increment of carbonyls concentrations began in the morning $(9: 00 \mathrm{~h}, \mathrm{BT})$ in spring and summer, and much earlier than that in autumn. The relatively higher humidity in spring and summer than in autumn might be in favor of HONO formation (the heterogeneous hydrolysis of $\mathrm{NO}_{2}$ on aerosol and particulate matter surfaces), which acts as an initiator to urban photochemistry (Atkinson, 2000) and might be the reason for the elevation of carbonyl concentrations at morning time in summer and spring. Compared with winter, the total elevation of carbonyls at any time of the day in other seasons was probably due to regional photo-oxidation of hydrocarbons.

The average values of the three carbonyl concentrations in each season are listed in Table 1. It is evident that the concentrations of ambient carbonyls in autumn, spring and summer were 

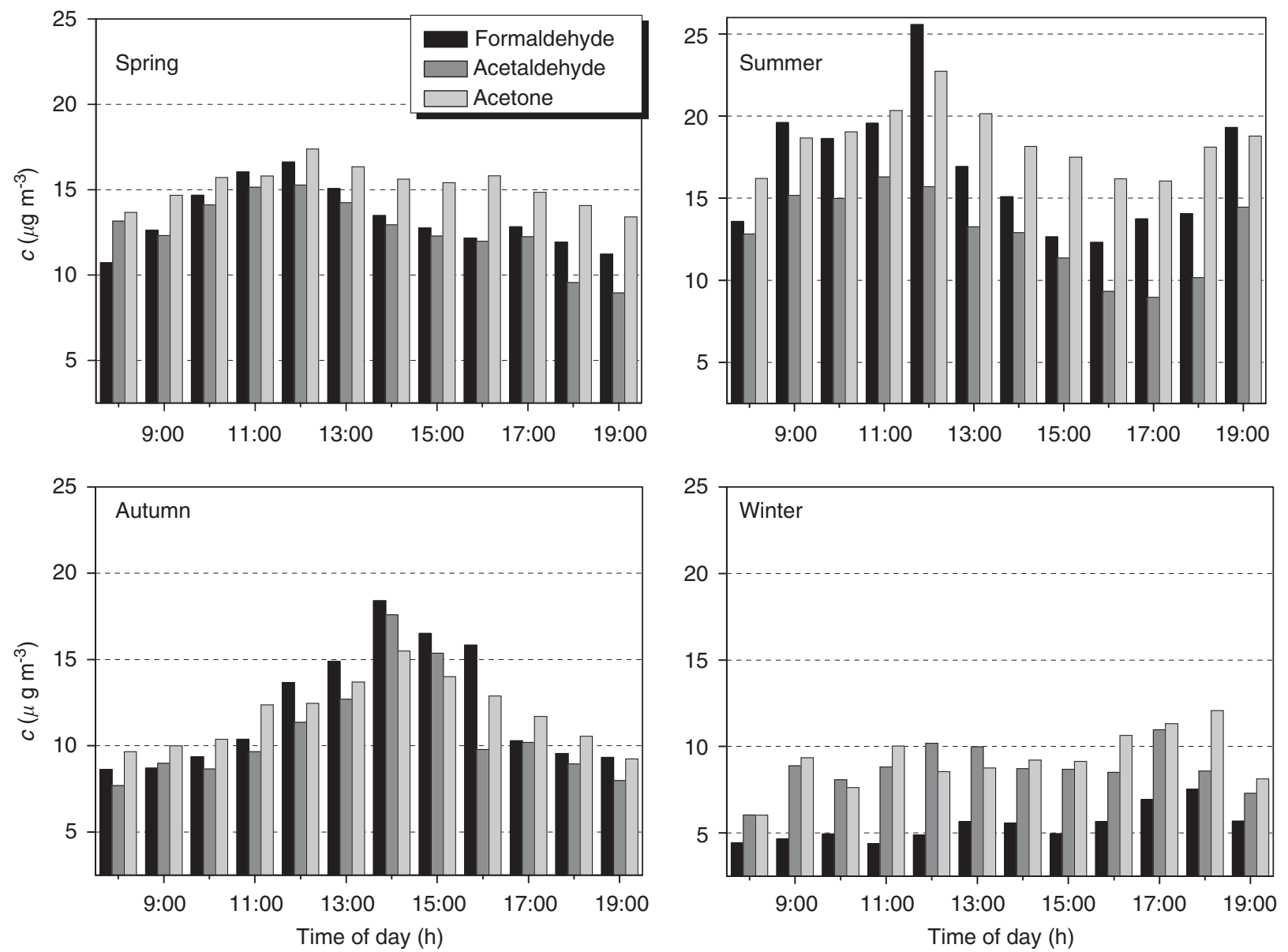

Fig. 2. Average diurnal variations of carbonyls in each season in Beijing urban ambient air.

Table 1

Seasonal variations of formaldehyde, acetaldehyde and acetone in urban ambient site (S1)

\begin{tabular}{|c|c|c|c|c|c|c|c|c|}
\hline & \multicolumn{2}{|c|}{ December-February 2004-05 } & \multicolumn{2}{|c|}{ March-April 2005} & \multicolumn{2}{|c|}{ June-August 2005} & \multicolumn{2}{|c|}{ September-November 2005} \\
\hline & Mean \pm SD & Range & Mean \pm SD & Range & Mean \pm SD & Range & Mean \pm SD & Range \\
\hline Ambient site & $n=86$ & & $n=120$ & & $n=110$ & & $n=72$ & \\
\hline Formaldehyde & $4.2 \pm 2.8$ & $1.1-12.1$ & $14.5 \pm 8.7$ & $1.9-45.8$ & $19.5 \pm 8.9$ & $2.6-52.9$ & $15.8 \pm 9.7$ & $3.7-45.6$ \\
\hline Acetaldehyde & $7.6 \pm 5.3$ & $1.4-30.1$ & $12.5 \pm 6.6$ & $1.1-32.9$ & $14.1 \pm 7.4$ & $1.8-35.7$ & $16.2 \pm 7.2$ & $2.8-30.4$ \\
\hline Acetone & $7.8 \pm 4.6$ & $1.8-25.3$ & $16.2 \pm 7.2$ & $1.3-38.7$ & $20.7 \pm 9.9$ & $6.8-50.6$ & $16.7 \pm 7.5$ & $5.3-33.1$ \\
\hline
\end{tabular}

Sampling time: 08:00-20:00 h (BT) $\left(\mu \mathrm{g} \mathrm{m}^{-3}\right)$.

significantly higher than that in winter. As mentioned above, the higher concentrations of the carbonyls in the three seasons might be mainly due to the photo-oxidation of VOCs. Assuming that carbonyls in winter totally come from direct anthropogenic emission, and the strength of this direct emission was same as that in other seasons, and the influence of meteorological conditions was neglected, the contributions of photo-oxidation of VOC to measured formaldehyde could be roughly estimated from the data of Table 1 as $71 \%, 78 \%$ and $73 \%$, respectively for spring, summer and autumn. These values estimated by us agreed very well with the results of Possanzini et al. (2002) and Solberg et al. (2001) who pointed out that photochemical formation accounted for $80-90 \%$ of the 
carbonyl products in summer. It should be noted that our rough estimation might have underestimated the contribution of photo-oxidation. First, because thermal inversions usually happen after the passage of cold air currents in winter in Beijing, air pollutants were easily built up under these conditions, e.g., the carbon monoxide (CO) concentration measured by the monitor station in our institute was obviously higher in winter than in other seasons. Second, the photodecomposition rates of carbonyls were much faster in other seasons than in winter (as discussed below). Finally, photo-oxidation of hydrocarbons also had minor contribution to measured carbonyls (as the evidence of small increment of carbonyls in noontime) in winter. Therefore, the local and regional photo-oxidation of hydrocarbons were the dominant sources of carbonyls in the seasons other than winter in Beijing.

\subsection{Relationship among carbonyls, ozone and CO}

To further confirm the above conclusion that atmospheric photo-oxidation is the dominant sources of ambient carbonyls in summer, the correlations among carbonyls, ozone and $\mathrm{CO}$ in summer and in winter were calculated as shown in Table 2. A typical diurnal variation of measured carbonyls and ozone in a summer day (26 July 2005) is also shown in Fig. 3. It is evident that ozone and carbonyls showed a similar varying pattern, and their concentration peaks all appeared during 11:00-14:00 $\mathrm{h}$ (BT). This phenomenon provided direct evidence that the carbonyl levels were strongly affected by the atmospheric photo-oxidation processes in summer. The significant correlation (Table 2) between carbonyls (especially for formaldehyde) and ozone in summer also indicated the importance of photo-oxidation on carbonyls formation.

$\mathrm{CO}$ is considered as the mark of anthropogenic source because $\mathrm{CO}$ primarily originates from vehicular exhaust and coal burning (Possanzini et al., 1996; Moussa et al., 2006). The significant correlations between carbonyls (formaldehyde and acetaldehyde) and $\mathrm{CO}$ in winter indicated that the atmospheric formaldehyde and acetaldehyde in winter mainly originated from vehicular exhaust. As mentioned above, photo-oxidation also had a minor contribution to the formation of carbonyls (especially for formaldehyde) in winter as the evidence of significant correlation between formaldehyde and ozone in winter.

The significant correlations among the three carbonyls in winter indicated that they might mainly come from same sources (Possanzini et al., 2002). The correlations among the three carbonyls in summer were still significant but much less than in winter, indicating that complex sources might have different impact on the individual carbonyls.

Formaldehyde/acetaldehyde (F/A) ratio may be a useful indicator of the contribution from photooxidation of natural hydrocarbons on carbonyls

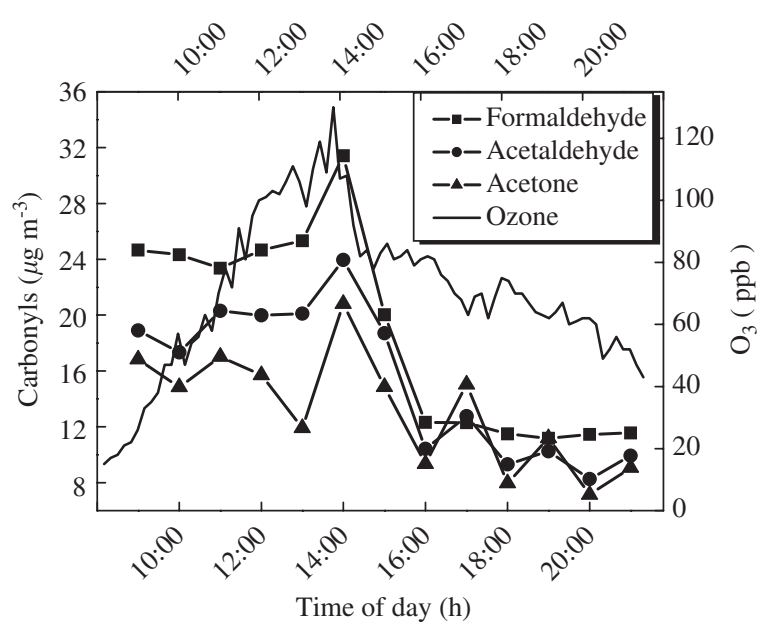

Fig. 3. Typical diurnal variations of carbonyls and ozone in Beijing urban ambient air in a summer day (26 July 2005).

Table 2

Correlation of carbonyls, ozone and $\mathrm{CO}$ in urban ambient air in summer and winter

\begin{tabular}{|c|c|c|c|c|c|c|c|c|c|c|}
\hline & \multicolumn{5}{|c|}{ December-February 2004-05 $(n=86)$} & \multicolumn{5}{|c|}{ June-August $2005(n=110)$} \\
\hline & Formaldehyde & Acetaldehyde & Acetone & Ozone & $\mathrm{CO}$ & Formaldehyde & Acetaldehyde & Acetone & Ozone & $\mathrm{CO}$ \\
\hline Formaldehyde & 1 & 0.89 & 0.79 & 0.70 & 0.64 & 1 & 0.77 & 0.69 & 0.84 & 0.21 \\
\hline Acetaldehyde & & 1 & 0.84 & 0.44 & 0.61 & & 1 & 0.78 & 0.82 & 0.14 \\
\hline Acetone & & 1 & 0.41 & 0.33 & 0.33 & & & 1 & 0.52 & 0.24 \\
\hline Ozone & & & 1 & 0.22 & 0.22 & & & & 1 & 0.15 \\
\hline $\mathrm{CO}$ & & & & 1 & 1 & & & & & 1 \\
\hline
\end{tabular}


level (Shepson et al., 1991). F/A ratios were reported to vary from about 1 in urban areas (Ho et al., 2002; Feng et al., 2005) to about 10 in deciduous forests (Jacob and Wofsy, 1988; Shepson et al., 1991). High values of $\mathrm{F} / \mathrm{A}$ ratio indicated that the photo-oxidation of natural hydrocarbons such as isoprene yielded more formaldehyde than acetaldehyde (Shepson et al., 1991; Duane et al., 2002). In this study, the seasonal average $\mathrm{F} / \mathrm{A}$ ratios were $0.86,1.041 .45$ and 1.94 for winter, autumn, spring and summer, respectively. The increment of $\mathrm{F} / \mathrm{A}$ ratio from winter to summer indicated that the photo-oxidation of natural hydrocarbons might play an important role in atmospheric carbonyl formation, especially in summer.

\subsection{Photolysis rates of carbonyls}

Photodecomposition is one of major sinks of carbonyls and plays an important role in the $\mathrm{OH}$ radical formation. The sink strength and contribution to $\mathrm{OH}$ of carbonyl photodecomposition are determined by their photolysis rates.

According to the mechanism of carbonyl photolysis and well-known calculation procedure (Finlayson-Pitts and Pitts, 1986; Possanzini et al., 2002), the photolysis rates of formaldehyde, acetaldehyde and acetone were calculated based on Beijing solar zenith angle in winter (14 January 2005)

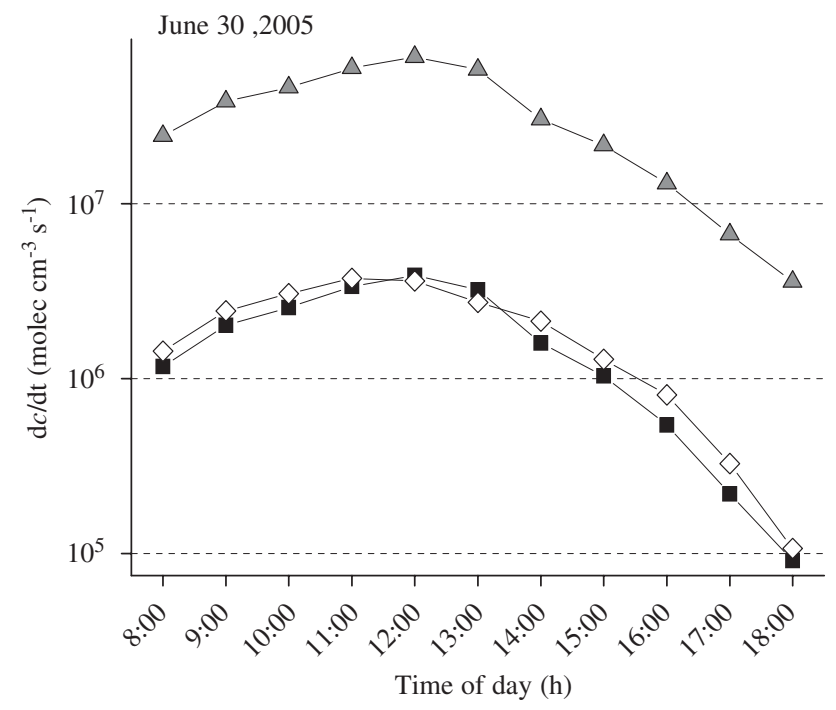

and in summer (30 June 2005) as shown in Fig. 4. Although carbonyls photolysis rates were 1-2 orders of magnitude faster in summer than in winter, the measured carbonyls concentrations were still several times higher in summer than in winter (Table 1). Therefore, the formation rates of carbonyls through photo-oxidation of VOC must greatly exceed their photolysis rates in summer. In addition, photodecomposition of carbonyls is an important source of $\mathrm{OH}$ radicals, which in turn accelerate photo-oxidation of hydrocarbons and further contribute to carbonyls formation.

\subsection{Carbonyl levels in various sites}

To understand the effect of local sources on the carbonyls levels, a comparison was conducted at five sites in Beijing and is summarized in Table 3. It was found that the carbonyl (formaldehyde and acetaldehyde) concentrations at transport hubs were about two times higher than those at urban ambient sites and commercial sites. The high level of carbonyls at the transport hub sites might be due to the direct strong source of vehicular exhaust. Compared with the three sites in Beijing urban area, the carbonyl levels were relatively lower in botanical park site (S2) and suburban site (S5), which are far away (about $30 \mathrm{~km}$ ) from Beijing urban area

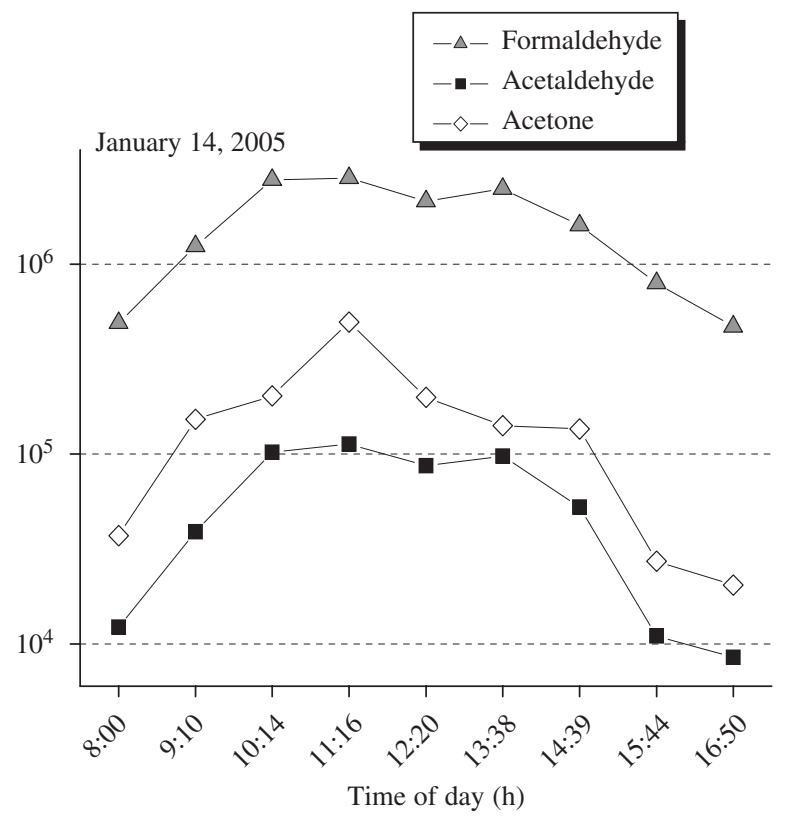

Fig. 4. Calculated photolysis rates of formaldehyde, acetaldehyde and acetone in Beijing urban ambient air during two typical sunny days in summer and winter. 
Table 3

Comparison of carbonyls levels among five sampling sites in spring $\left(\mu \mathrm{g} \mathrm{m}^{-3}\right)$

\begin{tabular}{|c|c|c|c|c|c|c|c|c|c|c|}
\hline & \multicolumn{2}{|c|}{ Urban ambient site } & \multicolumn{2}{|c|}{ Botanical park site } & \multicolumn{2}{|c|}{ Commercial site } & \multicolumn{2}{|c|}{ Transport hub site } & \multicolumn{2}{|c|}{ Suburban site } \\
\hline & Mean \pm SD & Range & Mean \pm SD & Range & Mean \pm SD & Range & Mean \pm SD & Range & Mean \pm SD & Range \\
\hline Sampling times & $n=120$ & & $n=20$ & & $n=42$ & & $n=60$ & & $n=10$ & \\
\hline Formaldehyde & $14.5 \pm 8.7$ & $1.9-45.8$ & $4.4 \pm 1.4$ & $2.5-7.8$ & $18 \pm 9.6$ & $12-36.7$ & $29.7 \pm 9.6$ & $9.8-57.6$ & $6.9 \pm 3.4$ & $4.3-10.8$ \\
\hline Acetaldehyde & $12.5 \pm 6.6$ & $1.1-32.9$ & $4.1 \pm 2.1$ & $1.5-7.2$ & $10.7 \pm 4.3$ & $8.3-18.9$ & $20.8 \pm 8.5$ & $7.6-34.6$ & $4.6 \pm 2.7$ & $2.1-6.8$ \\
\hline Acetone & $16.2 \pm 7.2$ & $1.3-38.7$ & $8.9 \pm 2.3$ & $6.4-12.6$ & $13.1 \pm 6.1$ & $9.7-23.6$ & $17.3 \pm 10.3$ & $6.3-42.5$ & $8.8 \pm 4.6$ & $5.7-11.4$ \\
\hline
\end{tabular}
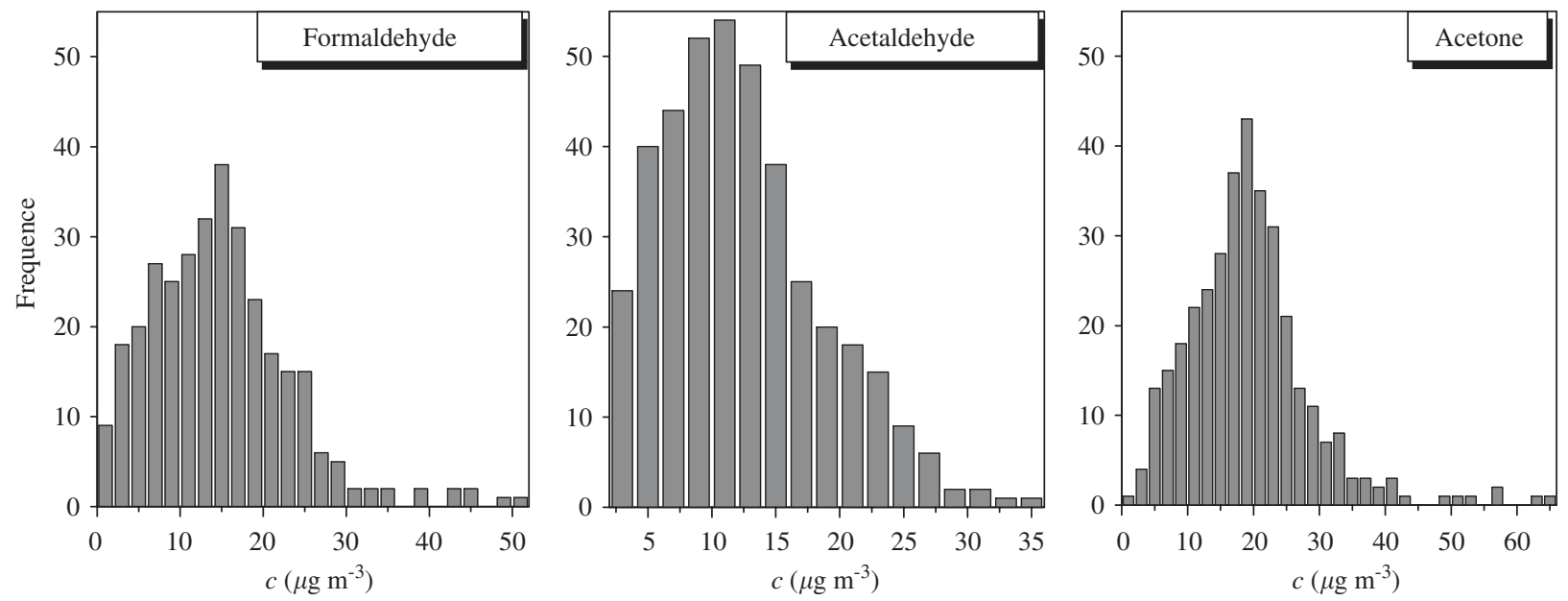

Fig. 5. Frequency distribution of formaldehyde, acetaldehyde and acetone for 350 data points measured in Beijing urban ambient air.

Table 4

Comparison between carbonyls level in Beijing and those in other cities $\left(\mu \mathrm{g} \mathrm{m}^{-3}\right)$

\begin{tabular}{lcccll}
\hline Locations & Formaldehyde & Acetaldehyde & Acetone & Sampling time & Ref. \\
\hline Beijing, China & 14.8 & 10.2 & 16.6 & November 2004-October 2005 & This work \\
Beirut, Lebanon & 5.7 & 4.1 & 12.9 & August-October 2004 & Moussa et al. (2006) \\
Guangzhou, China & 13.8 & 8.3 & 17.8 & June-September 2003 & Feng et al. (2005) \\
Hong Kong, China & 4.9 & 2.4 & 1.1 & October 1997-September 2000 & Sina et al. (2001) \\
Rio de Janeiro, Brazil & 10.8 & 10.4 & 4.1 & May-November 2000 & Grosjean et al. (2002) \\
Rome, Italy & 22.8 & 18.3 & 17.6 & June-July 1994, January-March 1995 & Possanzini et al. (1996) \\
New Mexico, USA & 18.6 & 13 & 11.1 & July-August 1993 & Gaffney et al. (1997) \\
Xalapa, Mexico & 3.7 & 21 & 8.4 & June, November, December, 1997 & Báez, et al. (2001) \\
Mexico City, Mexico & 43.5 & 28.6 & - & March-May, 1993 & Báez, et al. (1995) \\
Osaka, Japan & 10.1 & 7.5 & 1.3 & May-December 1997 & Nguyen et al. (2001) \\
\hline
\end{tabular}

and the influence from anthropogenic sources is relatively less.

\subsection{Frequency distribution and comparison with other cities}

Distribution frequency of pollutant concentrations is an effective indicator of air pollution level. As shown in Fig. 5, the frequency distributions of carbonyls were analyzed from the data points of 350 samples collected in the sampling site (S1). The concentrations of the highest frequency for formaldehyde, acetaldehyde and acetone were $9.0-19.0,5.0-15.0$ and $13.0-23.0 \mu \mathrm{g} \mathrm{m}^{-3}$, respectively, which occupied about $38 \%, 51 \%$ and $56 \%$ of the total data, respectively. Under stagnant 
air conditions with strong solar irradiation and high temperature, the ambient carbonyl concentrations increased dramatically to more than $30 \mu \mathrm{g} \mathrm{m}^{-3}$, which occupied about $4.0 \%, 3.0 \%$ and $8.8 \%$ of all data for formaldehyde, acetaldehyde and acetone, respectively. The annual average concentrations of formaldehyde, acetaldehyde and acetone were 14.8, 10.2 and $16.6 \mu \mathrm{g} \mathrm{m}^{-3}$, respectively.

Compared with other cities (Table 4), the carbonyl levels of Beijing were much higher than that of Hong Kong (Sina et al., 2001) and Osaka (Nguyen et al., 2001), and lower than that of Mexico City, which is one of cities with the most serious photochemical smog (Báez et al., 1995). On the whole, the carbonyl levels of Beijing are close to those fo Rio de Janeiro (Grosjean et al., 2002), Xalapa (Báez et al., 2001), New Mexico (Gaffney et al., 1997) and Rome (Possanzini et al., 1996).

\section{Conclusion}

The ambient levels and frequency distributions of lower carbonyls in Beijing were first recognized in this study. The diurnal variation of carbonyls in four seasons and the correlations between carbonyls and ozone as well as $\mathrm{CO}$ indicated that vehicular exhaust might be the major source for carbonyls in others seasons.

\section{Acknowledgments}

This work was financially supported by the Chinese National Natural Science Foundation (20577064), the Innovation Program of the Chinese Academy of Sciences and the National Basic Research Program of China (2005CB422206).

\section{References}

Atkinson, R., 2000. Atmospheric chemistry of VOCs and NOx. Atmospheric Environment 34, 2063-2101.

Báez, A.P., Belmont, R., Padilla, H., 1995. Measurements of formaldehyde and acetaldehyde in the atmosphere of Mexico City. Environmental Pollution 89, 163-167.

Báez, A.P., Padilla, H., Cervantes, J., Pereyra, D., Torres, M.C., Garcia, R., Belmont, R., 2001. Preliminary study of the determination of ambient carbonyls in Xalapa City, Veracruz, Mexico. Atmospheric Environment 35, 1813-1819.

Duane, M., Poma, B., Rembges, D., Astorga, C., Larsen, B.R., 2002. Isoprene and its degradation products as strong ozone precursors in Insubria, northern Italy. Atmospheric Environment 36, 3867-3879.
Feng, Y., Wen, S., Chen, T., Wang, X., Lv, H., Bi, X., Sheng, G., $\mathrm{Fu}$, J., 2005. Ambient levels of carbonyls and their sources in Guangzhou, China. Atmospheric Environment 39, 1789-1800.

Finlayson-Pitts, B.J., Pitts, J.N., 1986. Atmospheric Chemistry Fundamentals and Experimental Techniques. Wiley, New York.

Gaffney, J.S., Marley, N.A., Martin, R.S., Dixon, R.W., Reyes, L.G., Popp, C.J., 1997. Potential air quality effects of using ethanol-gasoline fuel blends: a field study in Albuquerque, New Mexico. Environmental Science and Technology 31, 3053-3061.

Grosjean, D., Grosjean, E., Moreira, L.F., 2002. Speciated ambient carbonyls in Rio de Janeiro, Brazil. Environmental Science and Technology 36, 1389-1395.

Grosjean, E., Grosjean, D., Seinfeld, J.H., 1996. Atmospheric chemistry of 1-octene, 1-decene, and cyclohexene: gas-phase carbonyl and peroxyacyl nitrate products. Environmental Science and Technology 30, 1038-1047.

Ho, K.F., Lee, S.C., Louie, P.K., Zou, S.C., 2002. Seasonal variation of carbonyl compound concentrations in urban area of Hong Kong. Atmospheric Environment 36, 1259-1265.

Jacob, D.J., Wofsy, S.C., 1988. Photochemistry of biogenic emissions over the Amazon forest. Journal of Geographical Research 93, 1477-1486.

Jacobson, M.Z., 2002. Atmospheric Pollution. Cambridge University Press, Cambridge, pp. 146-176.

Lary, D.J., Shallcross, D.E., 2000. Central role of carbonyl compounds in atmospheric chemistry. Journal of Geophysical Research 105, 19771-19778.

Moussa, S.G., El-Fadel, M., Saliba, N.A., 2006. Seasonal, diurnal and nocturnal behaviors of lower carbonyl compounds in the urban environment of Beirut, Lebanon. Atmospheric Environment 40, 2459-2468.

Nguyen, H.T., Takenaka, N., Bandow, H., Maeda, Y., Oliva, S.T., Botelho, M.M., Tavares, T.M., 2001. Atmospheric alcohols and aldehydes concentrations measured in Osaka, Japan and in Sao Paulo, Brazil. Atmospheric Environment 35, 3075-3083.

Possanzini, M., Palo, D., Petricca, M., Fratarcangeli, R., Brocco, D., 1996. Measurements of lower carbonyls in Rome ambient air. Atmospheric Environment 30, 3757-3764.

Possanzini, M., Di Palo, V., Cecinato, A., 2002. Sources and photodecompositon of formaldehyde and acetaldehyde in Rome ambient air. Atmospheric Environment 36, 3195-3201.

Shepson, P.B., Hastie, D.R., Schiff, H.I., Polizzi, M., Bottenheim, J.W., Anlauf, K., Mackay, G.I., Karecki, D.R., 1991. Atmospheric concentrations and temporal variations of C1-C3 carbonyl compounds at two rural sites in central Ontario. Atmospheric Environment 25A, 2001-2015.

Sina, D.W.M., Wong, Y.C., Louie, P.K.K., 2001. Trends of ambient carbonyl compounds in the urban environment of Hong Kong. Atmospheric Environment 35, 5961-5969.

Solberg, S., Dye, C., Walker, S., Simpson, D., 2001. Long-term measurements and model calculations of formaldehyde at rural European monitoring sites. Atmospheric Environment 35, 195-207.

WHO (World Health Organization), 1987. Air Quality Guidelines for Europe. WHO European Series No. 23, Copenhagen, Denmark. 